\title{
Is FNA Still a Useful Tool in the Diagnosis of Breast Masses? A 5-Year Review with Cytohistopathologic Correlation*
}

Astrid San Juan ${ }^{1}$ and Annette Salillas ${ }^{1,2}$

${ }^{1}$ Department of Pathology, Governor Celestino Gallares Memorial Hospital, Tagbilaran City, Philippines

${ }^{2}$ Southwestern University - Matias H. Aznar Memorial, College of Medicine, Cebu City, Philippines

\section{ABSTRACT}

Introduction. Breast cancer is the most common cancer among women worldwide. In the Philippine National Cancer registry, 1 in every 13 Filipino women is likely to suffer from breast cancer. Fine needle aspiration cytology (FNAC) is a safe, accurate, fast and economical technique practiced worldwide in breast cancer diagnosis.

Objective. To assess the value of FNAC as a rapid diagnostic tool in the local setting with the expectation to provide an immediate and highly reliable diagnosis in more than $90 \%$ of breast lesions.

Methodology. From January 2010 to December 2014, there were 306 out of 1465 breast FNAC documented cases with histopathological correlation. The FNAC smears were retrieved, retrospectively reviewed blindly and reclassified into 5 categories (C1-C5). All FNAC were performed by pathology residents, pathologists and cytopathologist. Smears were fixed in $95 \%$ ethyl alcohol and stained with Papanicolaou method.

Results. The FNAC findings showed: 13 (4.25\%) unsatisfactory (C1); 160 (52.29\%) benign (C2); 23 (7.52\%) atypical (C3); 9 (2.94\%) suspicious (C4) and 101 (33.01\%) malignant cases (C5). There were 120 (39.22\%) malignant and 186 (60.78\%) benign lesions. There were 3.92\% (12/306) false negative and $0.65 \%$ (2/306) false positive cases.

The FNAC had $90 \%$ sensitivity, $99 \%$ specificity, $98 \%$ positive predictive value, $99 \%$ negative predictive value and $95 \%$ accuracy. The risks of malignancy for each category were: $C 1=15 \% ; C 2=4 \% ; C 3=13 \% ; C 4=78 \%$ and C5 $=100 \%$.

Conclusion. Despite the increasing preference for core needle biopsy among surgeons, FNAC continues to be an acceptable, affordable, quick and valuable tool contributing significantly to early breast cancer diagnosis and treatment, particularly in developing countries like the Philippines. Owing to its high sensitivity and specificity, it can be used as a screening and confirmatory diagnostic tool. Malignant and benign interpretations of breast FNAC give highly accurate prediction of outcomes but must be correlated with clinical and mammographic findings.

Key words : fine needle aspiration cytology, breast, cytohistopathological correlation

\section{ISSN 0118-3265}

Printed in the Philippines.

Copyright $\odot 2017$ by the PJP.

Received: 31 March 2016.

Accepted: 14 June 2016.

Published online first: 14 December 2016.

https://doi.org/10.21141/PJP.2017.003

Corresponding author: Astrid T. San Juan, MD, MPM

E-mail: altmd2010@gmail.com

* This paper was presented in part as poster at the 19th International Cytology Congress, May 28 to June 1, 2016 at Yokohama, Japan.

\section{INTRODUCTION}

Breast cancer is the most common cancer in the Philippines, comprising 16 percent of the 80,000 cancer cases in 2010. The country has the highest incidence of breast cancer in Asia and an estimated 3 out of 100 Filipino women will have the disease before age 75 with mortality rate of 1 out of 100 according to the Philippine Society of Medical Oncology in 2012. ${ }^{1}$ It has become so common that one out of every thirteen Filipina is expected to have this disease. Early detection and accurate diagnosis of breast lesions is imperative for the appropriate medical management.

Fine needle aspiration (FNA) cytology has become a widely used and cost-effective tool in the assessment of breast masses., ${ }^{2,3}$ The current practice is to classify cytological results into one of the five categories ranging from C1 (insufficient material); C2 (benign); C3 (atypical); C4 (suspicious) and C5 (malignant). ${ }^{4}$ This system helps the cytopathologist define uncertain areas and for clinicians to properly manage their patients. The standardization for reporting breast cytology cases was initiated by Britain's National Health Service Breast Screening Programme. ${ }^{5}$ It serves as a common language among all health care professionals involved in breast care management. 
Specifically, C1 refers inadequate aspirate smear due to hypocellularity, aspiration, smearing or staining errors. The exact definition of what constitutes an adequate aspirate and whether or not a diagnosis could be confidently made with the quantity and quality of the aspirate remain a subjective issue and are best resolved by the pathologist. C2 category is for smears that are usually cellular, showing the characteristic patterns of different benign lesions. No atypical or malignant features are present. Usually, duct configurations, myoepithelial cells, and bipolar nuclei are visible. An inflammatory background is commonly encountered. In contrast, $\mathrm{C} 3$ and $\mathrm{C} 4$ are gray zones. C3 represents the characteristics of a smear with benign features that are not usually seen in clearly benign specimens such as cellular crowding, pleomorphism, and discohesion. C4 is reserved for aspirates where atypical features are obvious but factors such as poor preservation, hypocellularity, or components of a benign smear are present, thus precluding a firm diagnosis of malignancy. This ambiguity shows the importance of correlation with other disciplines. C5 category consists of cellular aspirates with evidently malignant cytologic features. ${ }^{6}$

The Pathology Department of Governor Celestino Gallares Memorial Center, provides diagnostic service on cytological studies to the entire province of Bohol. On average, the department conducts 800 - 1100 fine needle aspiration cytological examination of masses from different sites per year. The data profile of breast cases in our institution has not been fully established. Studies on FNA cases focusing on the breast alone have not been done to assess the diagnostic performance and accuracy of the procedure.

\section{REVIEW OF RELATED LITERATURE}

\section{Diagnostic Performance of fine needle aspiration cytology}

Fine needle aspiration cytology has become widely accepted as a reliable diagnostic tool for diagnosis breast masses. It is a simple and safe method which yields high diagnostic performances. ${ }^{7,8}$ In 2009, a study in Thailand reviewed diagnostic performances of FNA in breast lesions; the sensitivity of the test was 87.6-94.8\% with a specificity of $85.9-94.5 \%$ and positive predictive value of 83.4-92.8\% negative predictive value of 90.4-97.4\% and accuracy of $87.6-94.8 \%$ with false positive and false negative rates of $5.5 \%$ and $3.3 \%$ respectively. ${ }^{9}$ Another recent meta-analytical review, including 25 studies of FNA, has shown that FNA cytological analysis of palpable breast masses is highly accurate to differentiate benign from malignant tumors. ${ }^{10}$ Core needle biopsy has mostly replaced FNA in Europe and the United States. ${ }^{11,12}$ However, it is still commonly used in Asia and other developing countries with low financial resources. ${ }^{13,14}$

\section{Breast Cancer Experience in the Philippines}

Breast cancer has been consistently the most common cancer among Filipino women. With an age-standardized incidence rate (ASR) of 47.7 per 100,000 women (1998), it was second only to lung cancer when both male and female cancers were considered. ASRs had increased (1980 - 1992), female residents in highly urbanized cities in Metro Manila were experiencing similar rates in Europe, South America and Oceania. One out of 28 Filipinos who live up to 64 years, and one of 19 who live up to 74 will have breast cancer. ${ }^{15}$

In 2000, a local clinical practice guideline from the Philippine College of Surgeons was created recommending patients with a palpable breast mass and in which cancer is suspected. Fine needle aspiration cytology (FNAC) is the initial diagnostic procedure in patients with palpable breast mass. If the FNAC results are benign but clinical findings are highly suspicious for breast cancer, either a core needle or an open biopsy is done. Philippine standards on FNAC have not been established. ${ }^{16}$

\section{OBJECTIVES}

\section{General objective:}

- To assess the value of FNAC as a rapid diagnostic tool in the local setting with the expectation to provide an immediate and highly reliable diagnosis in more than $90 \%$ of breast lesions.

\section{Specific objectives:}

- To determine the sensitivity and specificity of FNAC as a diagnostic tool.

- To determine the risk of malignancy of the individual categories (C1 - C5).

\section{METHODOLOGY}

Fine needle aspiration biopsy (FNAB) is done by pathology residents, pathologists, and cytopathologist in the Histopathology Section of the Governor Celestino Gallares Memorial Hospital, a research and training institution in Bohol, Philippines. These were palpation-guided using a G23 x 1" needle attached to a $5.0 \mathrm{ml}$ syringe. Direct conventional smears were prepared from each pass and immediately fixed in $95 \%$ ethyl alcohol, then stained using the Papanicolaou method and read by the consultant pathologist on duty. Turnaround time of FNAB results varied from 30 minutes (routine cases) to 1 hour (difficult cases).

During the study period of January 2010 - December 2014, all breast fine needle aspiration cytology cases were retrieved from the cytology logbooks with approval from the research and ethics committee of the institution. Patient demographic data such as age, sex, clinical and FNA findings were included. Ultrasonography and mammogram data were not included in the study since not all patients had them. FNAC without final histopathological findings and histopathological specimens without prior FNAC were not included in this study. The FNA cytology cases were retrospectively reviewed and reclassified according to the National Health Service Breast Screening Programme (NHSBSP) standards: unsatisfactory (C1), benign (C2), atypical (C3), suspicious (C4) and malignant (C5).

Fine needle aspiration biopsy results that were found to have inadequate or acellular findings such as benign cyst contents, suppurative material, bloody aspirate, abscess, inflammatory cyst, collagenized stroma with rare benign ducts, adipose tissue and fibrosis, and inflammatory lesions with suspicious granulomas were reclassified as C1. C2 were diagnoses of benign conditions such as epidermal inclusion cyst, fibroadenoma, fibroadenoma with fibrocystic changes, fibrocystic changes alone, non-proliferative fibrocystic lesion, non-proliferative breast lesion, proliferative breast lesion including those with lactational changes with minimal atypia and without atypia; proliferative fibrocystic lesion including those without atypia, papillary neoplasm, spindle cell tumor, and suppurative granulomatous mastitis. Proliferative breast lesions and fibrocystic lesions with atypia were reclassified as C3.

Results favoring a more malignant diagnosis were reclassified as $\mathrm{C} 4$ or $\mathrm{C} 5$. Cases with results such as suspicious for phyllodes tumor, mammary carcinoma, ductal carcinoma in situ or malignant lymphoma were reclassified as C4. C5 were cases with clear cut malignant findings such as ductal, lobular or papillary carcinoma, high grade sarcoma or carcinoma, mucinous carcinoma and carcinoma with ductal, papillary or mucinous features. 
Corresponding available histopathological specimens of all FNAC were retrieved and compared. These specimens were primarily obtained from lumpectomies and mastectomies. Core needle biopsy specimens were used when no other sample was available. Concordance of findings between the FNAC and final histopathological outcome were investigated through blind microscopic rescreening of slides by a most senior pathologist. True negative results were cases which turned out to have benign outcomes on final tissue biopsy. True positive results were cases which had malignant outcomes. C1 - C3 Categories were considered to support a benign process while C4 - C5 Categories favor a malignant process. Accuracy, precision, sensitivity and specificity of the procedure were calculated.

\section{RESULTS AND DISCUSSION}

From January 2010 to December 2014, there were a total of 5043 fine needle aspiration biopsies done, of which 1465 (29\%) were breast cases, composed of 1389 females and 76 males. The average age was 52 years (range, 10 - 88 years). A total of 13262 histopathological specimens were received by the pathology department but only $715(5 \%)$ were breast related. There were 306 fine needle aspiration biopsies with corresponding final histopathology specimens (303 females and 3 males) available for the entire study duration (Table 1).

The majority of breast cytology results $(160 ; 52.29 \%)$ were the benign C2 category. The malignant C5 was the second largest category at 101 (33.01\%). The atypical C3 category ranked third with 23 cases $(7.52 \%)$ while unsatisfactory $\mathrm{C} 1$ category had 13 cases $(4.25 \%)$ and suspicious $\mathrm{C} 4$ category had 9 cases only (2.94\%) (Figure 1). Individual diagnoses per category were tabulated in Table 2.

When the final histopathological outcomes were reviewed, there were 120 (39.22\%) malignant and 186 (60.78\%) benign lesions (Figure 2). Tumor diameters of the malignant and benign cases ranged from $0.8 \mathrm{~cm}$ to $10 \mathrm{~cm}$. The maximum number of benign cases was in the age group of 20-24 years while the malignant cases peaked in the age group of 45 to 49 years (Table 3). For the individual categories, there were 2 out of $13 \mathrm{C} 1$ cases, 7 out of $160 \mathrm{C} 2$ cases, 3 out of $23 \mathrm{C} 3$ cases, 7 out of $9 \mathrm{C} 4$ cases and 101 out of $101 \mathrm{C} 5$ cases that turned out to be malignant. The risks of malignancy for each category were as follows: $15 \%$ for C1, 4\% for C2, 13\% for C3, 78\% for C4 and 100\% for C5 (Figure 3). Individual histopathological results per category are listed in Table 4.

\section{Final Histopathological Outcomes}

\section{Cl unsatisfactory category}

The final histopathological specimens of the 13 cases in the $\mathrm{C} 1$ category yielded 11 benign (5 fibroadenoma with fibrocystic changes, 5 fibrocystic changes and 1 ductal hyperplasia with intraductal papilloma) and 2 malignant (2 invasive ductal carcinomas) outcomes. The rescreen process of the FNA slides

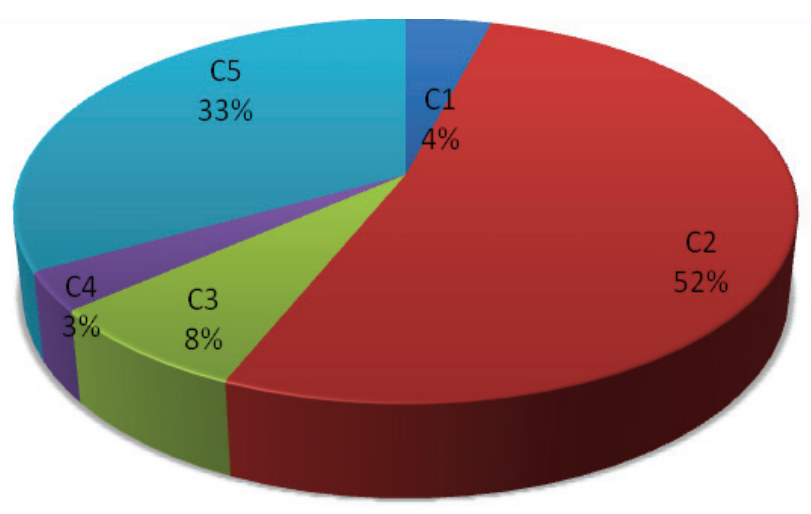

Figure 1. Percentage of breast fine needle aspiration cytology cases per category (C1- C5).

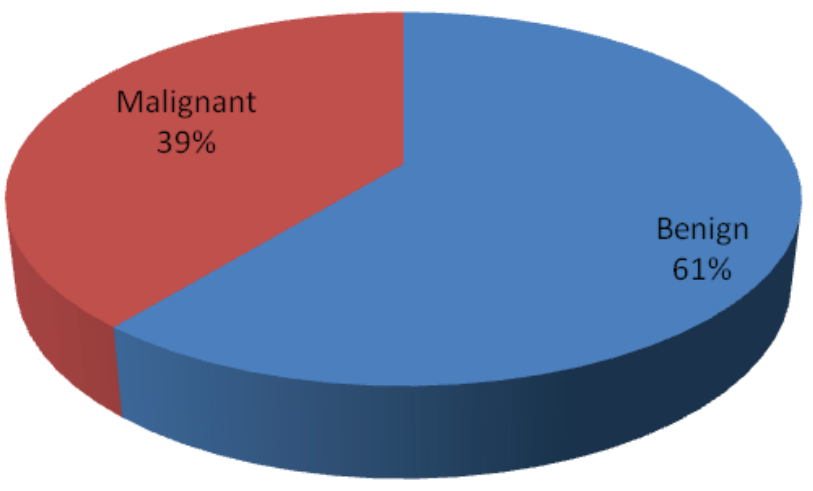

Figure 2. Final histopathological outcomes of submitted breast specimens for $2010-2014$.

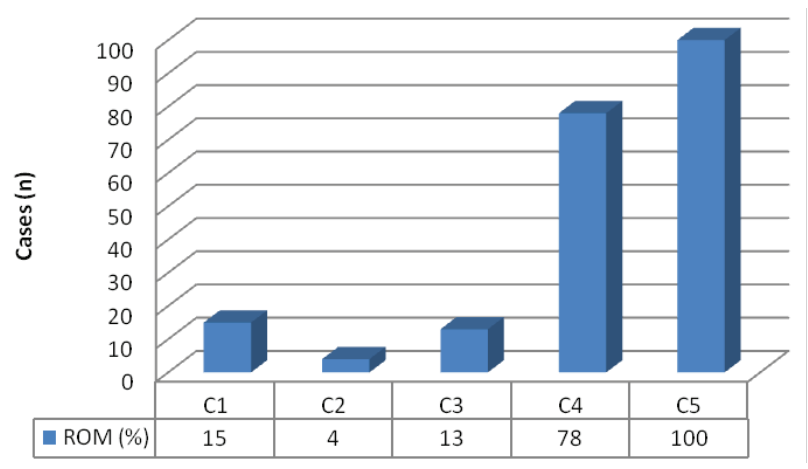

Figure 3. Risk of malignancy of the $\mathrm{C} 1-\mathrm{C} 5$ categories.

of one malignant case showed that there was a pre-analytical error of suboptimal sampling or missed sampling due to abundance of cyst fluid (more than $10 \mathrm{cc}$ ) with a deep seated malignant tumor that was not reached by the aspirating needle. The other case was missed because the cells that turned out to be malignant were obscured amidst severe inflammation, hemorrhage and necrotic background, reflecting the skill of the reader and the limitation of conventional smear.

Table 1. Total number of fine needle aspiration biopsies and histopathological specimens received per year (2010 - 2014) with corresponding number of breast cases

\begin{tabular}{|c|c|c|c|c|c|c|c|c|c|c|c|c|c|}
\hline Total Number & 2010 & BREAST & 2011 & BREAST & 2012 & BREAST & 2013 & BREAST & 2014 & BREAST & TOTAL (BREAST) & $\mathbf{F}$ & M \\
\hline FNA & 827 & 264 & 1011 & 302 & 1079 & 319 & 1123 & 302 & 1003 & 278 & 1465 & 1389 & 76 \\
\hline HP & 2441 & 124 & 2774 & 139 & 2726 & 172 & 2620 & 128 & 2701 & 152 & 715 & & \\
\hline FNA+HP & & 54 & & 58 & & 88 & & 57 & & 50 & 306 & 303 & 3 \\
\hline
\end{tabular}




\section{Table 2. Diagnoses in 306 breast masses on FNAC}

C1. UNSATISFACTORY SAMPLES $(\mathrm{n}=13)$

Benign cyst contents

Suppurative materials

C1. UNSATISFACTORY SAMPLES $(n=13)$

Inflammatory breast lesions

Mastitis

Breast abscess

Gynecomastia

Fibroadenoma

Fibroadenoma with fibrocystic changes

Fibroepithelial neoplasm

Non-proliferative breast lesion without atypia

Non-proliferative fibrocystic lesion without atypia

Papillary Neoplasm

Proliferative breast lesion with lactational changes

Proliferative breast lesion without atypia

Proliferative breast lesion with mild atypia

Proliferative fibrocystic lesion without atypia

Proliferative fibrocystic disease with mild atypia

Phyllodes tumor

Lipoma

Soft tissue tumor

C3. ATYPICAL CATEGORY $(\mathbf{n}=\mathbf{2 3})$

Proliferative breast lesion with moderate atypia 1

Proliferative breast lesion with atypia

Proliferative fibrocystic lesion with atypia

Spindle cell tumo

C4. SUSPICIOUS CATEGORY ( $\mathrm{n}=9)$

Suspicious for phyllodes tumor, high grade 2

Suspicious for mammary carcinoma

C5. MALIGNANT CATEGORY $(n=101)$

Ductal carcinoma 94

Lobular carc

Mucinous carcinoma

Carcinoma with mucinous features

Metastatic carcinoma
11

2

1

1
1

36

1
5

24

5

51
2

1

1

13

5

4

7

Experience and technique of the aspirator are the most important factors for specimen adequacy and interpretation of results. ${ }^{17,18}$ Referred slides from biopsies done by clinicians are usually insufficient and often require repeating procedure by a trained pathologist. ${ }^{19}$ The sensitivity of aspiration cytology of the breast has been reported to drop significantly $(98.2 \%$ to $75 \%)$ when done by an untrained individual. ${ }^{20,21}$ Technique plays an important role. ${ }^{17}$ In this study, the pathologists had variable years of training. The senior pathologist had the least numbers of insufficient specimens and missed lesions.

Imaging such as sonographic and stereotactic guidance is another factor affecting diagnostic accuracy. The cystic, deep seated lesion in this study could have benefited from ultrasound guided - FNAC. Thus, the need to diagnose patients with a combination of physical examination, radiological studies and FNA (triple test) is emphasized.

Smearing, drying artifacts, background materials, thick smears and inadequate fixation were some of the drawbacks seen in conventionally prepared slides. ${ }^{22}$ A liquid based preparation could have been used in this study to minimize background inflammation and concentrate cellular material. ${ }^{23}$

\section{C2 benign category}

Of the $160 \mathrm{C} 2$ benign category cases, 153 were benign and 7 turned out to be malignant. Benign findings included 7 benign phyllodes tumor, 4 chronic granulomatous mastitis, 66 fibroadenoma, 38 fibroadenoma with fibrocystic changes, 28 fibrocystic changes, 1 galactocoele, 3 lipoma, 2 intracystic papilloma, and 4 cases of

Table 3. Age distribution of cases with benign and malignant breast disease on histology

\begin{tabular}{|c|c|c|c|c|c|c|c|c|c|c|c|c|c|c|}
\hline & $10-14$ & $15-19$ & $20-24$ & $25-29$ & $30-34$ & $35-39$ & $40-44$ & 45-49 & $50-54$ & 55-59 & $60-64$ & $65-69$ & $70-74$ & $75-79$ \\
\hline Benign & 2 & 18 & 36 & 14 & 13 & 26 & 27 & 22 & 10 & 7 & 7 & 2 & - & 2 \\
\hline Malignant & - & - & - & 2 & 3 & 8 & 19 & 23 & 17 & 19 & 5 & 11 & 10 & 3 \\
\hline
\end{tabular}

FNA - Fine Needle Aspiration, HP - Histopathology, F - female, M - Male

Table 4. Histopathological diagnoses in 306 breast lesions based on C1-C5 categories

\section{HISTOPATHOLOGICAL OUTCOMES}

\section{BENIGN}

Acute and/or Chronic mastitis

Benign phyllodes tumor

Ductal hyperplasia with intraductal papilloma

Fibroadenoma

Fibroadenoma with fibrocystic changes

Fibrocystic changes

Galactocoele

Gynecomastia

Intracystic papilloma

Lipoma

Papillary Lesion

\section{MALIGNANT}

Ductal Carcinoma In Situ

Invasive Ductal Carcinoma

Invasive Ductal Carcinoma with lobular features

Intracystic Papillary carcinoma

Invasive Lobular Carcinoma

Invasive Papillary Carcinoma

Malignant phyllodes tumor

Mucinous Carcinoma

High grade carcinoma with sarcoma features

TN - True Negative, TP - True Positive, FN - False Negative, FP - False Positive

Table 5. Diagnoses in 306 breast masses on FNAC

\begin{tabular}{lrl}
\hline PARAMETER & Value (\%) & PARAMETER \\
\hline True Positive & $108(35 \%)$ & Accuracy \\
True Negative & $184(60 \%)$ & Sensitivity \\
False Positive & $3(1 \%)$ & Specificity \\
False Negative & $12(4 \%)$ & Positive predictive value (PPV) \\
& & Negative predictive value (NPV) \\
\hline
\end{tabular}


tissue fragments suggestive of a papillary lesion. There were 2 ductal carcinoma in situ, 3 invasive ductal carcinomas, 1 papillary carcinoma and intracystic papillary carcinoma.

On rescreening of the 7 false negative C2 cases, majority were pre-analytical errors of suboptimal sampling. The masses were seen to have minimal or rare atypia on FNA. This atypia was usually seen in hyperplastic changes. These patients were likewise young $(<40$ years old), favoring a more benign process. Another difficulty encountered was the interpretation of papillary lesions. The smears showed moderate cellularity composed of more uniform tall and columnar cells with elongated uniform small, deceptively bland- looking nuclei. The lack of cytomorphological clues of malignancy in these cases led to false negative findings. Indeed, the cytologic diagnosis of papillary lesions remains to be a challenge as experienced by other investigators. ${ }^{24,25}$

\section{C3 atypical category}

Of the $23 \mathrm{C} 3$ atypical cases, 3 turned out to be malignant and 20 benign. There were three cases of invasive ductal carcinoma which were noted to have abundant atypical cells on FNA. Those with benign outcomes included 3 fibroadenomas, 2 fibroadenomas with fibrocystic changes, 6 fibrocystic changes, 3 benign phyllodes tumors, 5 intracystic papillomas and 1 acute on chronic mastitis.

This category has been overused by most pathologists when insufficient atypia is seen to fulfill criteria for a malignant diagnosis. In this study, the percentage of C3 cases that turned out to be malignant was $15 \%$. The frequency of a diagnosis of a malignant lesion in this category is highly dependent on the skill and experience of the reader.

\section{C4 suspicious category}

Seven of 9 C4 suspicious category cases turned out to be malignant and were composed of 4 invasive ductal carcinomas, 2 invasive papillary carcinomas, and 1 malignant phyllodes tumor. Benign outcomes included 2 fibroadenomas with fibrocystic changes (FAFCC).

Rescreen of FNA slides of the FAFCC revealed scattered atypical cells with high nuclear to cytoplasmic ratio. The atypical cells appear slightly larger than the normal ductal epithelial cells and comprised more than $20 \%$ of the cell population. Pre-analytical and analytical error may have occurred due to missampling and wrong interpretation of the smears.

\section{C5 malignant category}

All FNAs that were categorized as C5 turned out to be malignant on their corresponding tissue specimens. The 101 histopathological outcomes were distributed among 89 invasive ductal carcinoma, 3 invasive ductal carcinoma with lobular features, 2 invasive lobular carcinoma, 4 invasive papillary carcinoma, 2 mucinous carcinoma and 1 high grade carcinoma with sarcomatous features.

The overall accuracy, precision, sensitivity, specificity, positive and negative predictive value were summarized in Table 5 . Sensitivity $(90 \%)$ and specificity $(99 \%)$ values of this study were similar to other studies conducted. ${ }^{26-29}$ The false positive $(0.65 \%)$, false negative $(3.92 \%)$ and accuracy $(95 \%)$ of this study also fell within the target values as described in other studies. ${ }^{6,30}$

Both PPV (98\%) and NPV (99\%) of FNAC are high and are comparable to other larger studies reported in literature. ${ }^{31,32} \mathrm{~A}$ high sensitivity and positive predictive value proves that a positive
FNAC in the breast means having comparable diagnosis with the final histopathology report. The high specificity and negative predictive value for malignancy demonstrates the high accuracy in the diagnosis of malignancy in the breast using FNAC.

\section{CONCLUSION}

Fine needle aspiration cytology is still recognised as an important tool in the diagnosis of malignancy in palpable breast masses despite the increasing preference of clinicians for core needle biopsies. It remains a popular procedure due to its cost-effectiveness, rapidity and reliability especially to low income countries such as the Philippines. However, it is emphasized that FNAC requires clinical and radiologic correlation to reduce false positive and false negative results.

\section{RECOMMENDATIONS}

Mammography and breast ultrasound studies are strongly recommended to improve diagnostic accuracy especially for patients with large, cystic breast masses and young patients with strong family history for breast cancer.

\section{ACKNOWLEDGMENTS}

The authors acknowledge the assistance of the histopathology section head, medical technologist assistant and nurse research assistant with the manual retrieval of documents and slides. They would like also to mention the assistance of Dr. Emelisa Almocera for proofreading the paper.

\section{AUTHOR DISCLOSURE}

The authors declared no conflicts of interest.

\section{FUNDING SOURCE}

None.

\section{REFERENCES}

1. Tubeza PC. 2012. Breast cancer is the most prevalent in the Philippines. Philippine Daily Inquirer, 18 October, A4. http://newsinfo.inquirer.net/291078/breast-cancer-is-the-mostprevalent-in-ph.

2. Feoli F, Paesmans M, Van Eeckhout P. Fine needle aspiration cytology of the breast: impact of experience on the accuracy, using standardized cytologic criteria. Acta Cytol. 2008:52(2):145-151. https://doi.org/10.1159/000325472.

3. Nagar S, Iacco A, Riggs T, Kestenberg W, Keidan R. An analysis of fine needle aspiration versus core needle biopsy in clinically palpable breast lesions: a report on the predictive values and cost comparison. Am J Surg. 2012;204(2):193-198. https://doi.org/10.1016/j.amjsurg.2011.10.018.

4. National Breast Cancer Centre. Breast fine needle aspiration cytology and core biopsy: a guide for practice. Camperdown, NSW, Australia: National Breast Cancer Centre, 2004. https:/canceraustralia.gov.au/sites/default/files/publications/ fna-fine-needle-aspiration-cytology-and-core-biopsy-guide-forpractice_504af03488799.pdf.

5. Mendoza P, Lacambra M, Tan PH, Tse GM. Fine needle aspiration biopsy of the breast: the non-malignant categories. Patholog Res Int. 2011;2011:547580. https://doi. org $/ 10.4061 / 2011 / 547580$. 
6. Zakhour H, Wells C. Diagnostic cytopathology of the breast. London, UK: Churchill Livingstone. 1999;8:261-6.

7. Koss LG. The palpable breast nodule: a cost-effectiveness analysis of alternate diagnostic approaches. The role of the needle aspiration biopsy. Cancer. 1993, 72(5):1499-502. PMID: 8348484.

8. Rubin M, Horiuchi K, Joy N, Haun W, Read R, Ratzer E, et al. Use of fine needle aspiration for solid breast lesions is accurate and cost-effective. Am J Surg. 1997; 174(6)694- 8. PMID: 9409599.

9. Nguansangiam S, Jesdapatarakul S, Tangiitgamol S. Accuracy of fine needle aspiration cytology from breast masses in Thailand. Asian Pac J Cancer Prev. 2009;10(4):623-6. PMID: 19827882.

10. Akçil M, Karaağaoğlu E, Demirhan B. Diagnostic accuracy of fine-needle aspiration cytology of palpable breast masses: an SROC curve with fixed and random effects linear metaregression models. Diagn Cytopathol. 2008;36(5):303-10. https://doi.org/10.1002/dc.20809.

11. Britton PD, Flower CDR, Freeman AH, Sinnatamby R, Warren R, Goddard MJ, et al. Changing to core biopsy in an NHS breast screening unit. Clin Radiol. 1997;52(10):764-7. https://doi.org/10.1016/S0009-9260(97)80156-0.

12. Cobb CJ, Raza AS. Obituary: "Alas poor FNA of breast we knew thee well!”. Diagn Cytopathol. 2005;32(1):1-4. https:// doi.org/10.1002/dc.20189.

13. Chaiwun B, Settakorn J, Ya-in C, et al. Effectiveness of fineneedle aspiration cytology of breast: analysis of 2,375 cases from northern Thailand. Diagn Cytopathol. 2002;26(3):201-5. https://doi.org/10.1002/dc.10067.

14. Chaiwun B, Sukhamwang N, Lekawanvijit S, Sukapan K, Rangdaeng S, Muttarak M, et al. Atypical and suspicious categories in fine needle aspiration cytology of the breast: histological and mammographical correlation and clinical significance. Singapore Med J. 2005;46(1):706-9. PMID: 16308644.

15. Laudico AV, Esteban DB, Reyes LM, Liquido JC. Philippine Cancer Facts and Estimates. Manila: Philippine Society, Inc., 1998, pp. 24-25.

16. Matsuda MLDL, Laudico AV, Yosuico VED, Roxas FTR, Cabaluna ND, Blanco FJ. Evidence-based Clinical Practice Guidelines on the Diagnosis and Management of breast cancer part I. Early breast cancer. Philippine General Hospital, 2000, 2-12. http://pcs.org.ph/wp-content/uploads/2013/01/ebcpg_ breast1.pdf.

17. Patel JJ, Gartell PC, Guyer PB, Herbert A, Taylor I. Use of ultrasound localization to improve results of fine needle aspiration cytology of breast masses. J R Soc Med. 1988;81(1):10-12. PMCID: PMC1291418.

18. Yeoh GPS, Chan KW. Fine-needle aspiration of breast masses: an analysis of 1533 cases in private practice. Hong Kong Med J. 1998;4(3):283-7. http://www.hkmj.org/system/ files/hkm9809p283.pdf.

19. Padel AF, Coghill SB, Powis SJ. Evidence that sensitivity is increased and the inadequacy rate decreased when pathologists take aspirates for cytodiagnosis. Cytopathology. 1993;4(3):1615. https://doi.org/ 10.1111/j.1365-2303.1993.tb00081.x.
20. Cohen MB, Rodgers RP, Hales MS, Gonzales JM, Ljung BM, Beckstead JH, et al. Influence of training and experience in fine-needle aspiration biopsy in breast. Receiver operating characteristic curve analysis. Arch Pathol Lab Med. 1987;111(6):518-20.

21. Ljung BM, Drejet A, Chiampi N, Jeffrey J, Goodson WH III, Chew K, et al. Diagnostic accuracy of fine-needle aspiration biopsy is determined by physician training in sampling technique. Cancer. 2001;93(4):263-8. https://doi.org/10.1002/ cncr.9040.

22. Alwahaibi NY, Alfahdi HA, Bai UR. Fine needle aspiration cytology of 108 breast lesions with histopathologic correlation: a retrospective study. Annu Res Rev Biol. 2014;4(21):3244-50. https://doi.org/10.9734/ARRB/2014/10538.

23. Kontzoglou K, Moulakakis KG, Konofaos P, Kyriazi M, Kyroudes A, Karakitsos P. The role of liquid-based cytology in the investigation of breast lesions using fine-needle aspiration: a cytohistopathological evaluation. J Surg Oncol. 2005;89:758. https://doi.org/10.1002/jso.20190.

24. Ueng SH, Mezzetti T, Tavassoli FA. Papillary neoplasms of the breast: A review. Arch Pathol Lab Med. 2009;133:893-907. http://www.archivesofpathology.org/doi/pdf/10.1043/15432165-133.6.893.

25. Agoff SN, Lawton TJ. Papillary lesions of the breast with and without atypical ductal hyperplasia can we accurately predict benign behavior from core needle biopsy? Am J Clin Pathol. 2004:122(3):440-443. https://doi.org/10.1309/ NAPJMB0GXKJC6PTH.

26. Paramesh, Angshuman S, Kariappa TM. Correlation of fine needle aspiration cytology and histopathology in palpable breast lesions in 100 patients of KVG Medical College \& Hospital, Sullia, Karnataka. International Journal of Applied Research. 2015;1(8);422-7. http://www.allresearchjournal. com/archives/2015/vollissue8/PartG/1-8-48.pdf.

27. Mahajan NA, Bhale CP, Mulay SS. Fine needle aspiration cytology of breast lesions and correlation with histopathology a 2 year study. Int J Health Sci Res. 2013;3(2):55-65.

28. Chokshi MH, Mehta NP. Cytological study of palpable breast lumps (407 cases) with their histological correlation. Int J Med Sci Public Health. 2014; 3(2); 181-185. https://doi. org/10.5455/ijmsph.2013.191120134.

29. Shah PM, Vekariya PN, Bhalara R, Talwelker S, Dhruva G. Histocytological correlation study of breast lesion: a study of 150 cases. International Journal of Scientific Research. 2014;3(11):381-2.

30. Chaiwun, B and Thorner P. Fine needle aspiration for evaluation of breast masses. Curr Opin Obstet Gynecol. 2007;19(1):48-55. PMID: 17218852. https://doi.org/10.1097/ GCO.0b013e328011f9ae.

31. Medina-Franco H, Abarca-Pérez L, Cortés-González R, SotoGermes S,Ulloa JA, Uribe N. Fine needle aspiration biopsy: institutional experience. Rev Invest Clin. 2005;57(3):394-8.

32. Choi YD, Choi YH, Lee JH, Nam JH, Juhng SW, Choi C.Analysis of fine needle aspiration cytology of the breast: a review of 1,297 cases and correlation with histologic diagnoses. Acta Cytol. 2004;48(6): 801-6. PMID: 15581165. 